\title{
CD34 marks angiogenic tip cells in human vascular endothelial cell cultures
}

\author{
Martin J. Siemerink • Ingeborg Klaassen • \\ Ilse M. C. Vogels • Arjan W. Griffioen • \\ Cornelis J. F. Van Noorden · Reinier O. Schlingemann
}

Received: 20 October 2011/ Accepted: 20 December 2011/Published online: 17 January 2012

(C) The Author(s) 2012. This article is published with open access at Springerlink.com

\begin{abstract}
The functional shift of quiescent endothelial cells into tip cells that migrate and stalk cells that proliferate is a key event during sprouting angiogenesis. We previously showed that the sialomucin CD34 is expressed in a small subset of cultured endothelial cells and that these cells extend filopodia: a hallmark of tip cells in vivo. In the present study, we characterized endothelial cells expressing CD34 in endothelial monolayers in vitro. We found that
\end{abstract}

Electronic supplementary material The online version of this article (doi:10.1007/s10456-011-9251-z) contains supplementary material, which is available to authorized users.

M. J. Siemerink · I. Klaassen - I. M. C. Vogels ·

C. J. F. Van Noorden $(\bowtie) \cdot$ R. O. Schlingemann $(\varangle)$

Ocular Angiogenesis Group, Department of Ophthalmology and

Department of Cell Biology and Histology, University of

Amsterdam, Academic Medical Center, PO Box 22660, 1100

DD Amsterdam, The Netherlands

e-mail: c.j.vannoorden@amc.uva.nl

R. O. Schlingemann

e-mail: r.schlingemann@amc.uva.nl

M. J. Siemerink

e-mail: m.j.siemerink@amc.uva.nl

I. Klaassen

e-mail: i.klaassen@amc.uva.nl

I. M. C. Vogels

e-mail: i.m.vogels@amc.uva.nl

\section{A. W. Griffioen}

Angiogenesis Laboratory, Department of Medical Oncology, VU

Medical Center, Amsterdam, The Netherlands

e-mail: a.griffioen@vumc.nl

R. O. Schlingemann

Department of Clinical and Molecular Ophthalmogenetics,

The Netherlands Institute for Neuroscience, Royal Netherlands

Academy of Arts and Sciences (KNAW), Amsterdam,

The Netherlands
CD34-positive human umbilical vein endothelial cells show low proliferation activity and increased mRNA expression of all known tip cell markers, as compared to CD34-negative cells. Genome-wide mRNA profiling analysis of CD34-positive endothelial cells demonstrated enrichment for biological functions related to angiogenesis and migration, whereas CD34-negative cells were enriched for functions related to proliferation. In addition, we found an increase or decrease of CD34-positive cells in vitro upon exposure to stimuli that enhance or limit the number of tip cells in vivo, respectively. Our findings suggest cells with virtually all known properties of tip cells are present in vascular endothelial cell cultures and that they can be isolated based on expression of CD34. This novel strategy may open alternative avenues for future studies of molecular processes and functions in tip cells in angiogenesis.

Keywords Angiogenesis - Endothelial tip cell - Vascular endothelial cell cultures $\cdot$ CD34

\section{Introduction}

Angiogenesis is crucial in the pathogenesis of many chronic and potentially fatal diseases $[1,2]$. In order to promote vascular network expansion, sprouting angiogenesis requires a subset of specialized endothelial cells while the majority of cells remains quiescent in the pre-existing blood vessel. Among these highly specialized cells are tip cells, which coordinate multiple critical processes in a hierarchical way. Located at the leading edge of the vascular sprout, tip cells form cellular protrusions or filopodia to guide migration towards a source of angiogenic growth factors [3]. Simultaneously, they signal to adjacent endothelial cells via Delta-like ligand (DLL)-Notch interactions 
not to adapt the tip cell phenotype, but to maintain the proliferative stalk cell phenotype and to form a vascular lumen [3, 4]. Because tip cells comprise a distinct subpopulation of endothelial cells with a unique molecular signature, they constitute an attractive target for pro- and anti-angiogenic therapy. Yet to develop such therapeutic strategies, a thorough understanding of the regulation of tip cell functions and the genes involved is needed.

Research on tip cells predominantly relies on in vivo models of angiogenesis [3-11], especially on developmental retinal angiogenesis during the first postnatal week in mice. These studies have shown that the fate of endothelial tip cells is controlled by a number of different signaling pathways, including that of vascular endothelial growth factor (VEGF) $[2,3,9,11]$ and the Notch ligand DLL4 [4]. In vitro tests can provide critical information on many factors regulating angiogenesis in vivo and are essential first steps for preclinical validation of potential therapeutic targets. Whether the tip cell phenotype is present in 2-dimensional vascular endothelial cell cultures, and whether this subpopulation of cells can be isolated is experimentally unexplored.

We hypothesized that, within the context of vascular endothelial cell cultures, CD34 is a novel marker to select for endothelial cells with a tip cell phenotype in vitro. CD34 is a highly glycosylated transmembrane cell surface glycoprotein, expressed by hematopoietic stem and progenitor cells [12-14] and, on the luminal cell membrane of quiescent endothelial cells of small blood vessels and lymphatics [7, 15-20]. Consequently, freshly-isolated human vascular endothelial cells are $\mathrm{CD} 34$-positive $\left(\mathrm{CD} 34^{+}\right)$, but expression is rapidly lost when resting cells are cultured and forced into cell cycle [21, 22]. Interestingly, a small subset of CD34 ${ }^{+}$ cells remains present in later passages of primary endothelial cell cultures and also in immortalized endothelial cell lines [23]. In human umbilical vein endothelial cell (HUVEC) cultures, we previously observed that these $\mathrm{CD} 34^{+}$cells extend filopodia [7]. CD34 expression on endothelial tip cell filopodia was also detected during angiogenesis in human tumors and embryogenesis, and in mouse embryogenesis and wound healing $[7,19,20]$.

In order to further unravel the molecular mechanisms that induce and maintain tip cell identity and regulate their specific functions, we investigated these $\mathrm{CD} 34^{+}$cells in cultures of vascular endothelial cells. We show that this $\mathrm{CD} 34^{+}$-subset of endothelial cells have filopodia, low proliferation activity and that the $\mathrm{CD} 34^{+}$phenotype in endothelial cell cultures is regulated similarly to mechanisms that regulate the tip cell phenotype in vivo. We exploited positive selection of $\mathrm{CD}_{3} 4^{+}$vascular endothelial cells in vitro and compared their transcriptome to $\mathrm{CD} 34$-negative $\left(\mathrm{CD} 34^{-}\right)$ cells. Real-time PCR and microarray data analysis identified increased expression of all known genes previously associated with tip cells in vivo. Our results open alternative avenues of research that may help to understand the molecular processes and functions in angiogenesis in general, and of the specialized endothelial tip cell in particular.

\section{Materials and methods}

Cells and cell cultures

Primary HUVECs were isolated from umbilical veins by collagenase digestion according to a published method [24] and routinely grown in M199 basal medium (Gibco, Grand Island, NY, USA) supplemented with $10 \%$ human serum, $10 \%$ fetal bovine serum (Biowhittaker, Walkersville, MD, USA) and $1 \%$ penicillin-streptomycin-glutamine (Gibco). Umbilical cords were obtained from the Department of Obstetrics and Gynaecology (Academic Medical Center, Amsterdam, The Netherlands). HUVEC cultures between passages 1 and 3 were used for all experiments. EC-RF24 [23] (derived from HUVECs) and HMEC-1 [23] (derived from human dermal microvascular endothelial cells) were routinely grown in EGM-2 MV BulletKit (Lonza, Walkersville, MD, USA). EC-RF24 and HMEC-1 between passages 30 and 40 were used for all experiments. All cells were cultured in $0.2 \%$ gelatin-coated culture flasks at $37^{\circ} \mathrm{C}$ and $5 \% \mathrm{CO}_{2}$. HMEC-1 was a kind gift of Prof. Dr. P. Hordijk (Sanquin, Amsterdam, The Netherlands) and EC-RF24 was a kind gift of A.M. Klous (Academic Medical Center, Amsterdam, The Netherlands).

When indicated, cells were treated with VEGF (R\&D Systems, Minneapolis, MN, USA), basic fibroblast growth factor (bFGF) (Invitrogen, Carlsbad, CA, USA), or tumor necrosis factor-alpha (TNF- $\alpha)(10 \mathrm{ng} / \mathrm{ml}$; R\&D Systems) or tissue culture plates were coated with $0.2 \%$ gelatin $(w / v)$ in PBS containing DLL4 $(1 \mu \mathrm{g} / \mathrm{ml}$; R\&D Systems) or bovine serum albumin (Sigma-Aldrich, St Louis, MO, USA) as a control according to Harrington et al. [25].

Immunostaining of cell cultures

For immunofluorescence microscopy, third passage HUVECs were grown to confluence on gelatin-coated coverslips (Thermo Scientific, South Logan, UT, USA). Cells were fixed for $20 \mathrm{~min}$ with freshly-prepared $2 \%$ paraformaldehyde in PBS and blocked for $30 \mathrm{~min}$ in $10 \%$ normal goat serum in PBS at room temperature. For double immunostaining, cells were incubated overnight at $4{ }^{\circ} \mathrm{C}$ with antibodies directed against CD34 [7] (clone QBEND-10; Monosan, Uden, The Netherlands) and cadherin 5 (CDH5; also known as vascular endothelial cadherin (VE-Cadherin)) (Abcam, Cambridge, UK). Secondary antibodies were goat anti-mouse fluorescein isothiocyanate (FITC) and goat 
anti-rabbit Cyanine-3 (Cy3) (Jackson Laboratories, Bar Harbor, ME, USA). The coverslips were then mounted in Vectashield (Vector Laboratories, Burlingame, CA, USA) containing DAPI and examined using a wide-field fluorescence microscope (Leica, Heidelberg, Germany). As negative controls, primary antibody was omitted.

Immunohistochemistry of tissue samples

Vibratome sections from paraformaldehyde-fixed normal and pathologic human tissues were stained with anti-CD34 or anti-CD31 (clone EN4; Abcam) antibody as described previously [7].

The spheroid-based angiogenesis model

HUVECs (750 cells/spheroid) were seeded in methyl cellulose (Sigma-Aldrich) containing medium to form cell spheroids (http://spherogenex.de) [26]. After $24 \mathrm{~h}$, cells were embedded in collagen gel with or without bFGF (20 ng/ml, R\&D Systems) and allowed to sprout for $24 \mathrm{~h}$. Gels containing the spheroids were fixed with $2 \%$ paraformaldehyde in PBS overnight and immunostained as described above.

\section{Flow cytometric analysis}

Cell suspensions were obtained by TrypLE (Gibco) treatment of adherent endothelial cell monolayers. All immunofluorescent labeling and washing was performed in PBS containing $0.1 \%$ bovine serum albumin. Cells were fixed in $2 \%$ paraformaldehyde in PBS for $15 \mathrm{~min}$ at room temperature and incubated with anti-CD34-phycoerythrin (anti-CD34-PE; clone QBend-10; Monosan), anti-CD31allophycocyanin (anti-CD31-APC; eBioscience, San Diego, CA, USA), anti-CD146-FITC (Abcam), anti-CD14FITC (Becton Dickinson, Mountain View, CA, USA), anti-CD133-APC (Miltenyi Biotec, Bergisch Gladbach, Germany), and anti-CD117-APC (Becton Dickinson). Cells were analyzed by flow cytometry on a FACSCalibur (Becton Dickinson) in combination with FlowJo software (Tree Star, San Carlos, CA, USA).

Cell sorting and RNA isolation

HUVECs of passage 3 were sorted for CD34 expression at $3 \times 10^{7}$ cells/h under sterile conditions on a FACSAria (Becton Dickinson) and total RNA from both fractions $\left(\mathrm{CD}_{4} 4^{+}\right.$and $\mathrm{CD}^{-} 4^{-}$) was extracted using TRIzol (Invitrogen). The amount of total RNA was approximately $1 \mu \mathrm{g} /$ $10^{5}$ cells, as measured on a nanodrop (ND-1000; NanoDrop Technologies, Wilmington, DE, USA), and RNA quality was determined by Bioanalyzer 2100 traces (Agilent
Technologies, Santa Clara, CA, USA) according to the manufacturer's protocols.

\section{Quantitative PCR}

A 1- $\mu$ g aliquot of total RNA was DNase-I treated (amplification grade; Invitrogen) and reverse transcribed into first-strand cDNA using Superscript III and oligo(dT) ${ }_{12-18}$ (Invitrogen). Primer details are provided in Supplementary Table 1. NCBI BLAST confirmed specificity of the primers. The presence of a single PCR product was verified by both the presence of a single melting temperature peak and detection of a single band of the expected size on agarose gels. Non-template controls were included to verify the method and the specificity of the primers. Mean primer efficiency was $96 \% \pm 3 \%$. Real-time quantitative PCR (qPCR) was performed as described previously [27, 28], using a CFX96 real-time PCR detection system (Bio-Rad Laboratories, Hercules, CA, USA). Gene expression data was normalized with the geomean of $\beta$-actin and tyrosine 3-monooxygenase/tryptophan 5-monooxygenase activation protein, and zeta polypeptide (YWHAZ) gene expression data, as determined by NormFinder [29].

\section{Microarray analysis}

The GeneChip HT HG-U133 + PM Array Plate (Affymetrix, Santa Clara, CA, USA) system was used for microarray analysis. Technical handling of the microarrays was performed at the MicroArray Department (MAD) at the Swammerdam Institute for Life Sciences (University of Amsterdam, Amsterdam, The Netherlands). In short, biotinlabeled cRNA samples were prepared as described in the GeneChip 3'IVT express kit user manual (Affymetrix) using $0.1 \mu \mathrm{g}$ purified total RNA as template for the reaction and a $16 \mathrm{~h}$ incubation time. Hybridization, staining and scanning were performed in a GeneTitan MC Instrument (Affymetrix). The raw data are available at the Gene Expression Omnibus (GSE 34850) (http://www.ncbi.nlm.nih.gov/geo/). After passing array quality control, expression values for each array were calculated using the robust multi-array average (RMA) algorithm, (Affy package version 1.22.0) [30] available from the Bioconductor project (http:// www.bioconductor.org) for the $\mathrm{R}$ statistical language (http://cran.r-project.org). The normalized data was statistically analyzed for differential gene expression using ANOVA (Maanova package, version 1.14.0) [31] with a model that considered the presence of CD34 as a fixed effect and individual as a random effect. In order to quantify the effect of the presence of CD34 on gene expression, a permutation based statistical test (2,000 permutations) was performed, and all $P$ values were adjusted for false discovery-rate correction [32]. Corrected $P$ values of less than 0.15 
were considered to indicate significant differences. Modelbased $\log 2$ ratios of $\mathrm{CD} 34^{+}$signal to $\mathrm{CD} 34^{-}$signal were generated for each probe set. A list was generated that contained those probe sets for which an average absolute fold change of at least 2.0 was observed between $\mathrm{CD} 34^{+}$and CD34- samples.

Gene ontology analysis and statistics

Gene ontology (GO) term enrichment was performed with the two sets that were $\geq 2$-fold upregulated or downregulated with statistical significance, using the DAVID algorithm [33] with the total set of genes of the Affymetrix HG-U133A chip as background. The following GO terms were selected: GOTERM_BP_ALL (biological process), GOTERM_CC_ALL (cellular component) and GOTERM_MF_ALL (molecular function), with classification strategy 'high'. GO terms were assumed to be biologically relevant with an enrichment score of at least 2.5 and a Benjamini-Hochberg-corrected modified Fisher's exact $P$ value of less than 0.02. Benjamini-Hochberg statistics were used to correct $P$ value to be more conservative in order to lower family-wise false discovery rate [34].

Gene set enrichment analysis

Changes in the expression of functionally related genes at the genome-wide expression profile level were detected using gene set enrichment analysis (GSEA) (version 2.07; Broad Institute, Cambridge, MA, USA). For the analysis, genes represented by more than one probe were collapsed to the probe with the maximum value using the gene symbols [35]. Gene sets were generated from gene lists published by Strasser et al. [8], Del Toro et al. [5], and Harrington et al. [25]. Mouse gene symbols were converted to their human homologues (http://ncbi.nlm.nih.gov/homologene). Genes of which no human homologue could be found were excluded from the list. In this way, five gene lists were generated (1) Strasser et al. $\geq 2$-fold overrepresented in a microdisected tip-cell fraction; (2) Del Toro et al. $\geq 2$-fold upregulated genes in dll4+/- mouse retina; (3) Del Toro et al. $\geq 2$-fold downregulated genes in dll4+/- mouse retina; (4) Harrington et al. $\geq 1.5$-fold upregulated genes in DLL4-retrovirally-infected HUVECs; (5) Harrington et al. $\geq 1.5$-fold downregulated genes in control empty vector-infected HUVECs. Our data was then tested for enrichment in these five gene sets using GSEA, with the number of permutations set to 1,000 . False discovery rate (FDR) $Q$ value $<25 \%$ was used as criteria for significantly enriched gene sets.

\section{Live cell imaging}

Live cell imaging was performed according to a published method [36]. In brief, equal yields of $\mathrm{CD}^{+} 4^{+}$and
CD34- sorted HUVECs were seeded separately into a 6-well plate. After $12 \mathrm{~h}$ of incubation, the culture medium above the cells was layered with mineral oil (SigmaAldrich) to prevent evaporation of the medium. The 6-well plate was placed at $37^{\circ} \mathrm{C}$ in an atmosphere containing $5 \%$ $\mathrm{CO}_{2}$ under an inverted microscope (Leica) and phase contrast images were acquired at time intervals of $10 \mathrm{~min}$ for $48 \mathrm{~h}$ at 10 fixed spots in each cell culture. Time lapse movies were analyzed using custom-made software.

\section{Statistical analysis}

All cell culture experiments were performed in triplicate. Analysis of variance with significance $\alpha=0.05$ was used for processing the data. Statistical significance was determined using a two-tailed Mann Whitney $U$ test for qPCR data or a (paired) Student $t$ test for FACS and live cell imaging data. Prism 5 software (GraphPad Software Inc, San Diego, CA, USA) was used for statistical analysis.

\section{Results}

CD34 is expressed on filopodia of endothelial cells in angiogenesis in vivo

Luminal endothelial CD34 staining was observed to be ubiquitous in quiescent small blood vessels and capillaries in non-pathologic human tissues. However, in human colon carcinoma, in addition to the luminal endothelial membrane staining, a striking CD34 staining of abluminal filopodia was observed, extruding from endothelial cells at sites of active angiogenesis (Fig. 1). In serial sections

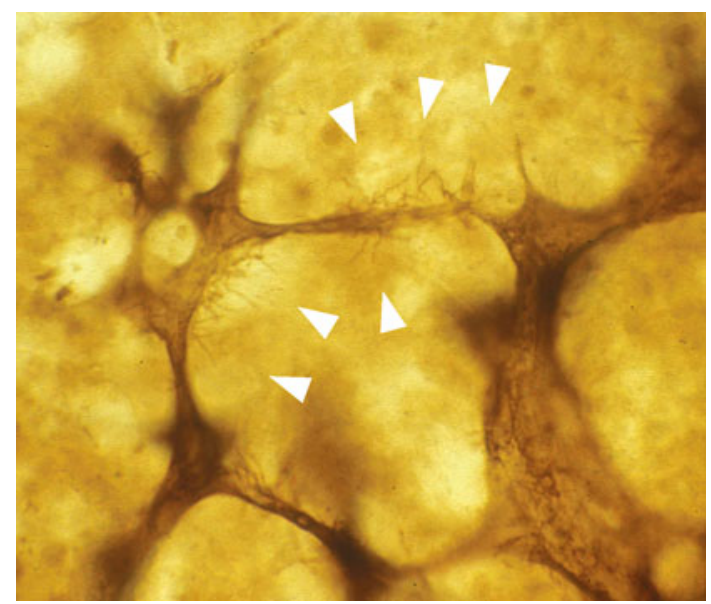

Fig. 1 CD34 is expressed on endothelial filopodial extensions at sites of active angiogenesis in vivo. Immunoperoxidase staining with antiCD34 monoclonal antibody QBEND-10 of a section of surgically removed human colon carcinoma lesion. Anti-CD34 antibody stains capillaries and numerous endothelial filopodia (arrowheads). $\times 450$ 
stained with anti-CD31 antibody, staining of filopodia was not observed (data not shown).

Morphological characterization of $\mathrm{CD} 4^{+}$cells in vascular endothelial cell cultures

Employing flow cytometry, we found that the mean proportion of $\mathrm{CD}_{3}{ }^{+}$cells in HUVEC cultures from 5 different donors was $11.9 \%$ (SD 3.0; range 7.4-15.9\%) at passage 3 (Fig. 2a). To study the morphological characteristics of the $\mathrm{CD}_{3} 4^{+}$HUVECs in vitro, we examined HUVECs in a confluent monolayer. Immunofluorescence microscopy showed a small fraction of $\mathrm{CD}^{+}{ }^{+}$cells, whereas the vascular endothelial cell marker VE-cadherin was readily detectable in every cell (Fig. 2b). In the fraction of HUVEC cells that expressed CD34, CD34 staining was detected on all cell membrane domains, but these $\mathrm{CD}^{+} 4^{+}$HUVEC cells had a distinct morphological appearance. They were often elongated, and demonstrated a polarized extension of CD34-marked filopodia located in one or two areas of their plasma membrane (Fig. 2b). These observations are in agreement with earlier reports describing that $\mathrm{CD}^{+} 4^{+}$HUVECs have morphological characteristics similar to tip cells in vivo, which have filopodia at the leading front of the cells [7].

To rule out the possibility that the $\mathrm{CD} 34^{+}$cells in HUVEC cultures were contaminating hematopoietic stem/ progenitor cells and to confirm the endothelial nature and purity of cells, we showed co-expression of the endothelial markers CD31, VE-cadherin and CD146, and excluded expression of stem cell markers CD133 and CD117 and the myelomonocytic marker CD14 (Fig. 3).

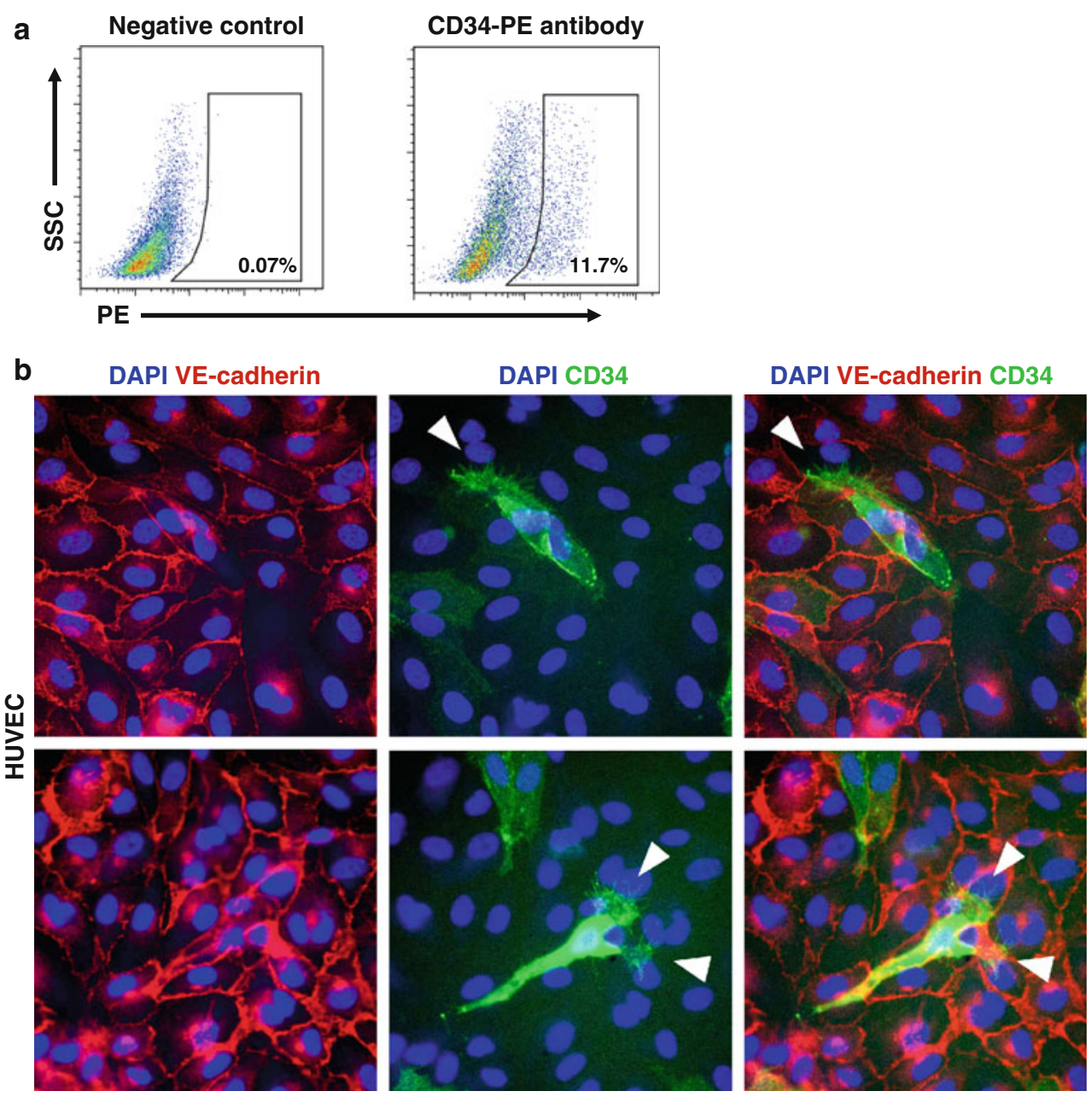

Fig. 2 Morphology of $\mathrm{CD} 34^{+}$cells in HUVEC cultures shows a strong resemblance with that described for tip cells in vivo. a Flow cytometric dot plots of HUVECs of one representative donor demonstrating the proportion of $\mathrm{CD} 34^{+}$cells in a HUVEC culture at passage 3. b Third passage HUVECs expressed VE-cadherin (red), but only a subset was stained for CD34 (green). Note filopodia extending from elongated CD $34^{+}$HUVECs (arrowheads), whereas adjacent CD34 ${ }^{-}$HUVECs show cobblestone morphology and lack of filopodia. DNA was stained with DAPI (blue). (Color figure online) 

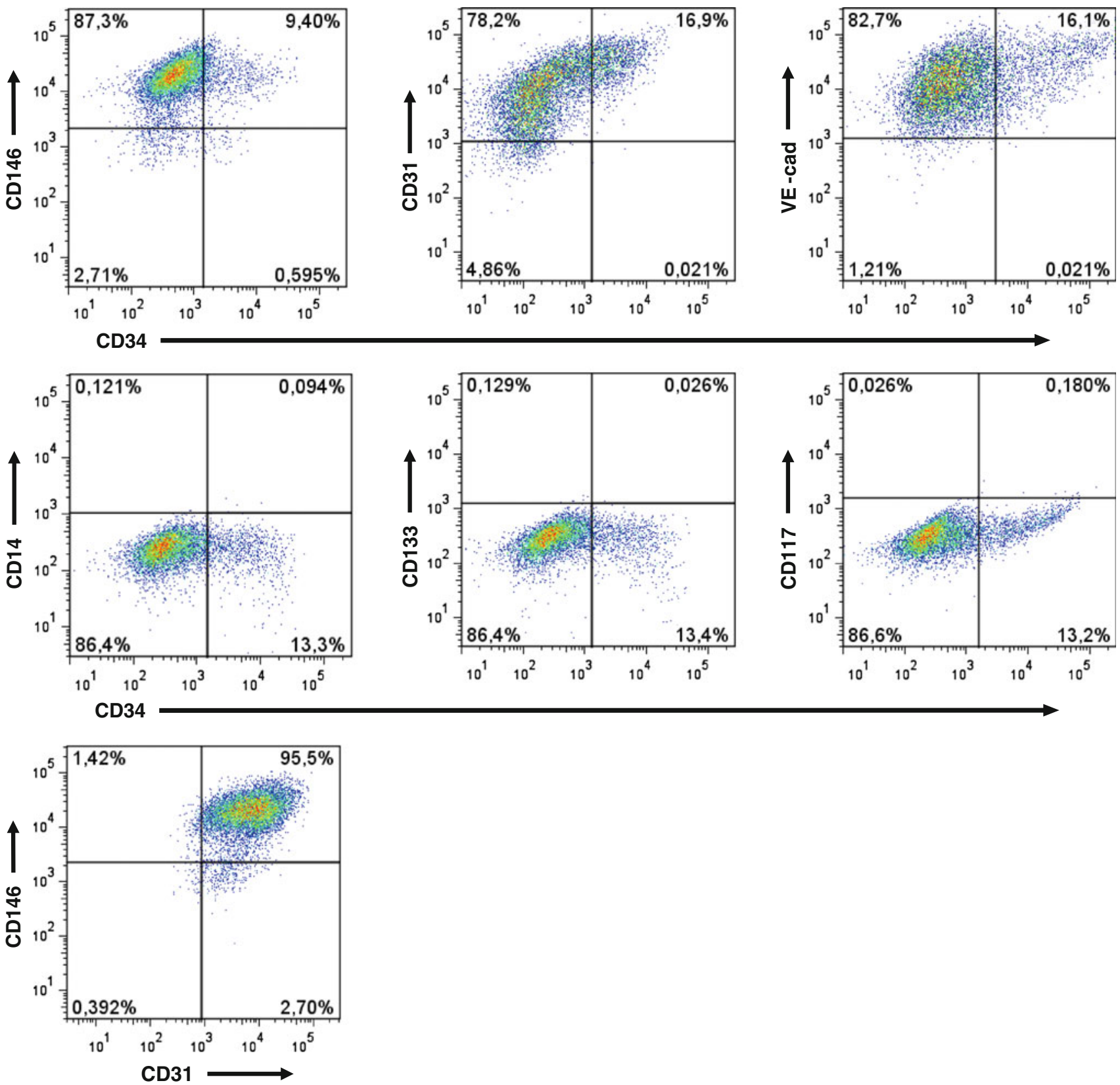

Fig. $3 \mathrm{CD}^{+} 4^{+}$cells in HUVEC cultures co-express endothelial markers. CD $34^{+}$HUVECs were analyzed by 2 -color flow cytometry for the expression of CD31, CD146 and VE-cadherin (endothelial cell specific markers), CD133 and CD117 (stem cell and endothelial

$\mathrm{CD} 34^{+}$cells are actively generated in endothelial cell cultures and show low proliferation activity

We investigated whether the $\mathrm{CD} 34^{+}$phenotype in culture is reversible, as recent observations in vivo have demonstrated that the positions and phenotypes of tip cells and stalk cells in sprouting vessels are reversible [37]. We found that $\mathrm{CD}^{-} 4^{-}$cells isolated from primary human endothelial cells were able to re-express CD34 when these

progenitor cell specific markers), and CD14 (myelomonocytic specific marker). The results demonstrate that all $\mathrm{CD} 34^{+}$cells are positive for CD31, CD146 and VE-cadherin, but negative for CD133, CD117 and CD14

cells were cultured again. After 10 days of culture, the relative subpopulation of $\mathrm{CD} 34^{+}$cells was of a similar magnitude compared to unsorted HUVECs (Fig. 4a, b). Re-expression of CD34 in CD34- ${ }^{-}$FACS-sorted cell cultures was also observed in 2 immortalized human endothelial cell lines, HMEC-1 and ECRF24 (data not shown).

Tip cells in vivo have low proliferation activity [3]. To further characterize the $\mathrm{CD} 34^{+}$cell population with respect to proliferation activity, we sorted HUVECs by FACS, 

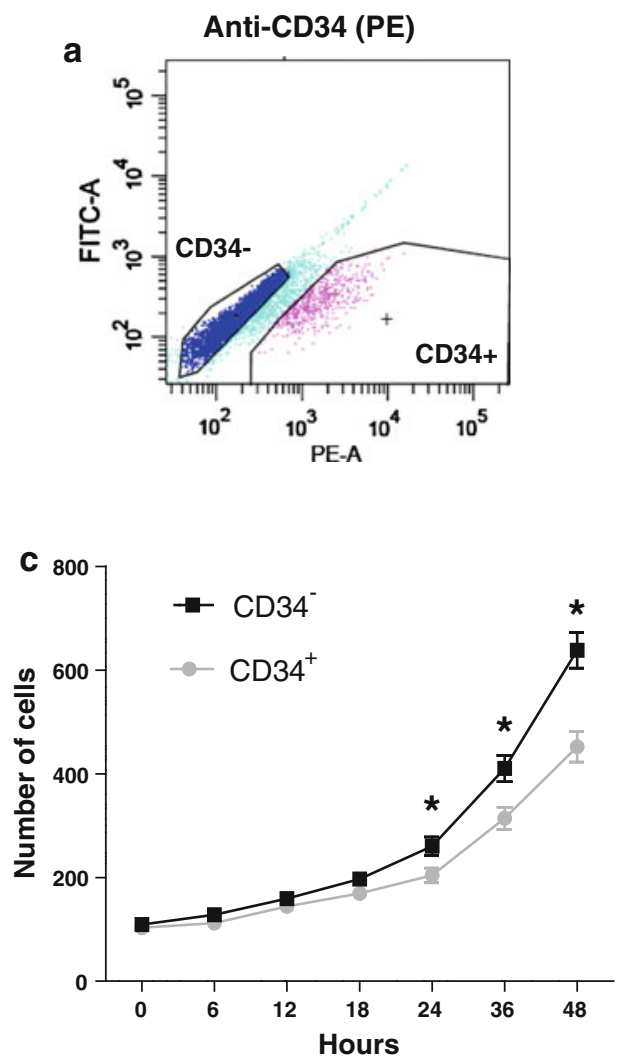

Fig. $4 \mathrm{CD}^{+} 4^{+}$cells in HUVEC cultures are actively generated and show a lower proliferation rate. a CD34- cells were sorted from HUVEC cultures using FACS and then cultured again. b After 10 days of culture, cells were analyzed for CD34 expression by FACS showing a subpopulation of $9.8 \%$ of $\mathrm{CD}^{+} 4^{+}$cells. SSC, side scatter. CD $34^{+}$and CD $34^{-}$FACS-sorted HUVECs were cultured separately for $48 \mathrm{~h}$ and images were taken every $15 \mathrm{~min}$ at 10 fixed spots in each

cultured $\mathrm{CD} 34^{+}$and $\mathrm{CD} 34^{-}$cells separately and analyzed cell proliferation through live-cell imaging. $\mathrm{CD} 34^{+}$ HUVECs showed fewer cells in mitosis as compared to CD34- HUVECs (Fig. 4c, d). We detected no differences in cell cycle time between $\mathrm{CD} 34^{+}$and $\mathrm{CD} 34^{-}$cells.

$\mathrm{CD} 34^{+}$phenotype in endothelial cell cultures is regulated by similar mechanisms that regulate the tip cell phenotype in vivo

Differentiation into the tip cell phenotype in vivo is controlled by a number of signaling pathways, including that of VEGF [2, 3, 38], TNF- $\alpha$ [39], and Notch ligand DLL4 [4]. In addition, binding of VEGF-A to VEGF receptor 2 (VEGFR2) in tip cells induces expression of DLL4, and subsequently DLL4 binds to Notch that is expressed on adjacent cells providing a signal inducing the stalk cell phenotype [4]. We determined whether the relative amount of $\mathrm{CD}_{3} 4^{+}$cells in vitro is also controlled by these 3 mechanisms. Third-passage HUVECs stimulated with
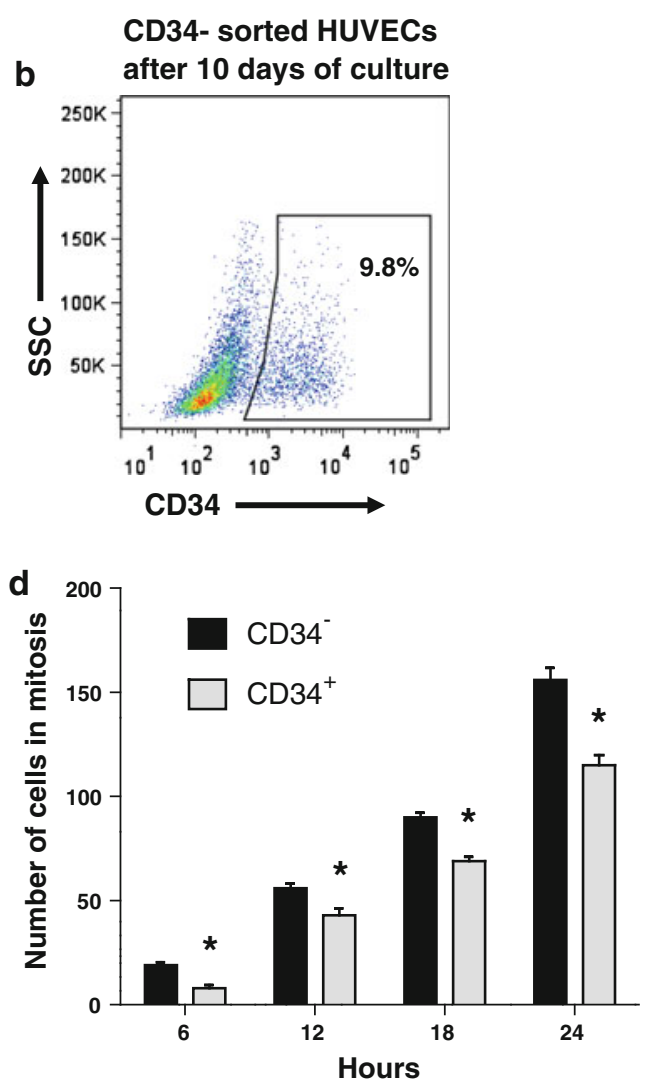

culture. Time-lapse movies were analyzed by counting the total amount of cells and the number of cells in mitosis, as recognized by the division of one cell into 2 daughter cells. c Numbers of cells at the given time points. d Total number of cells in mitosis. Shown are means and standard error of the means (SEM); * indicates $P<0.05$, relative to $\mathrm{CD}^{-} 4^{-}$, determined by Student $t$ test

VEGF showed an increased percentage of $\mathrm{CD}^{+} 4^{+}$cells whereas bFGF stimulation did not change the percentage of CD34 ${ }^{+}$cells (Fig. 5a). For VEGF, the response was dose dependent with a maximum effect at $25 \mathrm{ng} / \mathrm{ml}$. HUVECs continuously stimulated with $\mathrm{TNF}-\alpha$ showed a reduced number of $\mathrm{CD} 34^{+}$cells (Fig. $5 \mathrm{~b}$ ). In addition, we promoted the stalk cell phenotype by activating Notch signaling by culturing HUVECs on DLL4-coated dishes [25]. As predicted, this resulted in a decrease in the percentage of $\mathrm{CD} 4^{+}$cells (Fig. 5c). However, the $\gamma$-secretase inhibitor DAPT, which inhibit Notch receptor cleavage and signaling and leads to elevated numbers of tip cells in vivo [9], did not increase the percentage of $\mathrm{CD} 34^{+}$cells when added to HUVEC cultures.

Because monolayer HUVEC cultures may reflect only certain aspects of the angiogenic cascade, we subsequently studied CD34 expression on HUVEC in a 3-dimensional spheroid-based tube formation model [26, 40, 41]. Before embedding in collagen gel, HUVEC spheroids did not stain with anti-CD34 antibody (data not shown). After 

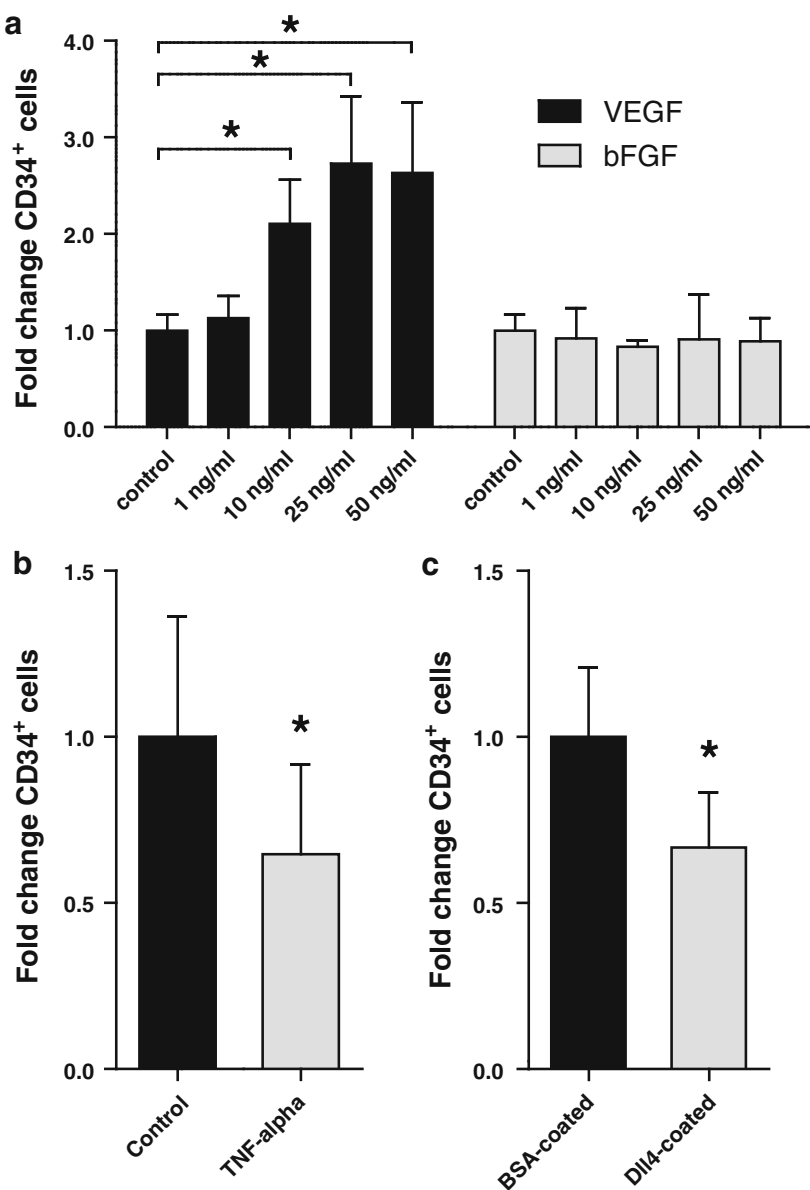

Fig. 5 The number of $\mathrm{CD} 34^{+}$cells on HUVECs in vitro is regulated by mechanisms known to induce or inhibit the tip cell phenotype in vivo. The proportion of CD $34^{+}$HUVECs was determined by flow cytometry after culturing of cells in the presence or absence of VEGF, bFGF, TNF- $\alpha$ or DLL4 for $48 \mathrm{~h}$. a Dose-dependent increase of CD34 expressing cells when stimulated with VEGF but not bFGF. b Continuous stimulation with TNF- $\alpha$ decreased the number of CD34 ${ }^{+}$HUVECs. c HUVECs cultured on DLL4-coated plates showed a lower number of $\mathrm{CD} 34^{+}$cells. Shown are mean and SD; * indicates $P<0.05$ relative to control, determined by Student $t$ test for paired samples

embedding in collagen gel containing FCS, only cells at the surface of the spheroids re-expressed CD34 (Fig. 6). After exposure to bFGF to induce sprouting angiogenesis, CD34 was expressed in the newly formed sprouts and on the filopodial extensions of the leading tip cells (Fig. 6), mimicking the expression pattern observed in angiogenesis in vivo $[7,17,19,20]$.

Gene expression of tip cell markers is increased in $\mathrm{CD} 34^{+}$endothelial cells in vitro

Besides expression of VEGFR2 and DLL4, other genes have been associated with the tip cell phenotype in vivo, including VEGFR3 [9, 11, 42], platelet-derived growth

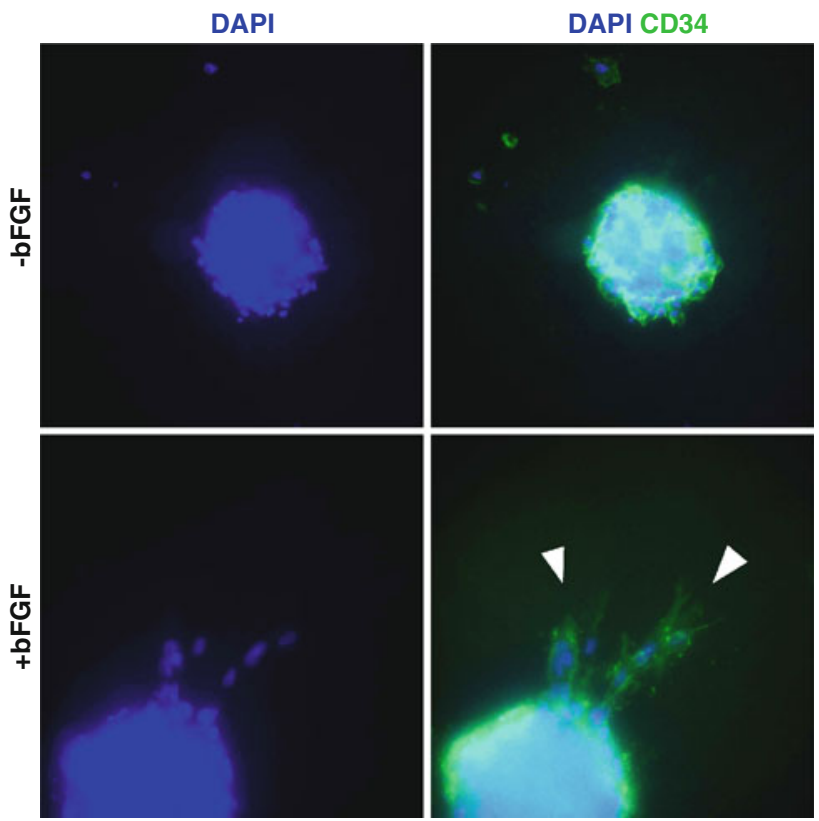

Fig. 6 CD34 on HUVECs in vitro is upregulated during angiogenesis and tip cell formation. 3-Dimensional in vitro angiogenesis of collagen-gel embedded HUVEC spheroids cultured in the presence or absence of bFGF after fixation and staining for the expression of CD34 (green). Arrowheads point at filopodial extensions of tip cells. (Color figure online)

factor B (PDGFB) [3], unc-5 homolog B (UNC5B) [43], roundabout homologue 4 (ROBO4) [44], ephrin-B2 (EFNB2) [6, 10], and neuropilin-1 (NRP1) and NRP2 [45, 46]. Two more recent studies identified expression of chemokine receptor type 4 (CXCR4), apelin (APLN), and angiopoietin-2 (ANGPT2) to be enriched in tip cells [5, 8]. We analyzed the expression of these genes in FACS-sorted $\mathrm{CD} 34^{+}$and $\mathrm{CD}^{-} 4^{-}$subpopulations of HUVECs by realtime qPCR. mRNA expression levels of all 13 presently known tip cell markers appeared to be increased in CD34 ${ }^{+}$ cells, and 9 out of 13 were significantly $(P<0.05)$ overexpressed (more than 2-fold) as compared to $\mathrm{CD} 34^{-}$cells (Table 1). We found a 121.8-fold overexpression of CD34 in $\mathrm{CD}_{3} 4^{+}$HUVECs, but no significant changes in expression levels of the other two CD34-family members podocalyxin-like 1 (PODXL1) and PODXL2 (Supplementary Table 2) [14].

CD34 ${ }^{+}$cells in HUVEC cultures are a model to study tip cell phenotype and function in vitro

To further test our hypothesis that CD34 uniquely marks endothelial cells with a tip-cell phenotype, and to further characterize gene regulation in $\mathrm{CD} 34^{+}$HUVEC cells, we performed Affymetrix cDNA microarray analysis in CD $34^{+}$versus $\mathrm{CD} 34^{-}$cells. We found 441 genes to be differentially expressed (more than 2-fold) with statistical 
Table 1 qPCR analysis comparing $\mathrm{CD}_{4} 4^{+}$to $\mathrm{CD}^{-} 4^{-}$sorted HUVECs revealed statistically significant enriched expression of 9 genes previously identified as tip cell markers in vivo. In bold, significant change

\begin{tabular}{|c|c|c|c|}
\hline $\begin{array}{l}\text { Gene } \\
\text { symbol }\end{array}$ & Full name & $\begin{array}{l}\text { Mean fold difference } \\
\text { CD } 34^{+} \text {compared to } \\
\text { CD34 }\end{array}$ & $P$ value \\
\hline VEGFR2 & $\begin{array}{l}\text { Kinase insert } \\
\text { domain receptor }\end{array}$ & 5.9 & 0.002 \\
\hline VEGFR3 & $\begin{array}{l}\text { Fms-related } \\
\text { tyrosine kinase } 4\end{array}$ & 1.8 & 0.180 \\
\hline NRP1 & Neuropilin 1 & 2.5 & 0.013 \\
\hline NRP2 & Neuropilin 2 & 4.8 & 0.003 \\
\hline PDGFB & $\begin{array}{l}\text { Platelet-derived } \\
\text { growth factor } \\
\text { beta polypeptide }\end{array}$ & 2.1 & 0.180 \\
\hline DLL4 & Delta-like 4 & 7.0 & 0.085 \\
\hline ANGPT2 & Angiopoietin 2 & 8.1 & 0.004 \\
\hline APLN & Apelin & 5.0 & 0.025 \\
\hline UNC5B & Unc-5 homolog B & 4.1 & 0.475 \\
\hline ROBO4 & $\begin{array}{l}\text { Roundabout } \\
\text { homolog } 4 \text {, magic } \\
\text { roundabout }\end{array}$ & 2.0 & 0.013 \\
\hline PLXND1 & Plexin D1 & 3.9 & 0.006 \\
\hline EFNB2 & Ephrin-B2 & 4.4 & 0.009 \\
\hline CXCR4 & $\begin{array}{c}\text { Chemokine (C-X-C } \\
\text { motif) receptor } 4\end{array}$ & 41.9 & 0.017 \\
\hline CD34 & CD34 molecule & 121.4 & 0.001 \\
\hline
\end{tabular}

significance ( $Q$ value $<0.15$ ), of which 172 were upregulated and 269 downregulated in the $\mathrm{CD} 34^{+}$population (Fig. 7a, Supplementary Table 3). The series of 172 upregulated genes was enriched for GO terms consistent with the tip cell phenotype in vivo, such as angiogenesis, regulation of cell migration and blood vessel morphogenesis (Fig. 7b). GO term analysis of the series of 269 downregulated genes showed enrichment for cell cycle processes, an observation that is consistent with the absent proliferation activity observed in tip cells (Fig. 7b) [3]. Transcriptional levels of a selection of over 25 differentially expressed genes selected from the microarray data were validated and confirmed by qPCR in 7 HUVEC donors sorted for CD34 (Supplementary Table 2). The upregulated expression levels of known tip cell markers were confirmed in the microarray analysis, as 9 out of 13 were significantly $(Q$ value $<0.15)$ overexpressed in CD $34^{+}$HUVECs (Supplementary Table 2).

We examined whether our microarray data show overlap with data of 2 microarray studies which investigated the tip and stalk cell transcriptome in vivo but employed different strategies [5, 8], and with a microarray study which investigated the effects of DLL4-Notch signaling in HUVECs [25]. GSEA showed that the gene sets positively correlating with a tip cell phenotype were significantly enriched $(P<0.05)$ in our $\mathrm{CD} 34^{+}$gene set, confirming that at least some of the genes that are upregulated in CD $34^{+}$HUVECs in our study are potentially bone fide tip cell markers. The highest correlation $(P<0.001)$ was found with the gene set of Del Toro et al. [5], who compared retinal endothelial cells isolated from the eyes of Dll4+/- and wild type mice.

Among the genes that showed upregulated expression in CD34 ${ }^{+}$HUVECs were the secreted molecules insulin growth factor-2 (IGF2), insulin-like growth factor binding protein 4 (IGFBP4) and adrenomedullin (Supplementary Table 2). Furthermore, we found a marked upregulation of CXCR4 and its ligand CXCL12 (also known as SDF-1) (Supplementary Table 2).

\section{Discussion}

In this study, we demonstrate that cells with virtually all the known properties of tip cells are present in 2-dimensional vascular endothelial cell cultures and that they can be isolated on the basis of CD34 expression. We found CD34 expression in a subset of HUVEC, HMEC-1 and ECRF24 cultures, in comparable numbers as observed in previous studies $[7,22,23]$. We demonstrated that the morphology of $\mathrm{CD} 34^{+}$cells in HUVEC cultures shows a strong resemblance to the appearance of tip cells in human tumors and developing mouse retina $[3,4,6,7,9,10]$. Key features of this similarity include their highly polarized nature, numerous filopodia probing the environment, and migration toward an angiogenic stimulus. Many in vivo angiogenesis models rely on these typical morphological aspects when studying tip cells, but to our knowledge, tip cells have not previously been identified in endothelial cultures in vitro.

We show that the percentage of cells expressing CD34 in endothelial cell monolayers in vitro appears to be regulated, at least partly, by similar mechanisms reported to regulate the endothelial tip cell phenotype in vivo. These findings strongly support our hypothesis that $\mathrm{CD} 34^{+}$cells in vitro represent true tip cells. In fact, stimulation of HUVECs with all three main known regulatory molecules of the tip cell phenotype, i.e. VEGF [3], TNF- $\alpha$ [39], and Notch ligand DLL4 [4], resulted in an increase or decrease of $\mathrm{CD}_{3} 4^{+}$cells in HUVEC cultures as predicted by our hypothesis. The maximum number of $\mathrm{CD} 34^{+}$cells that can be generated in a HUVEC monolayer by adding VEGF appeared to be limited in our model.

Both VEGF and bFGF are known to have potent angiogenic activities in vivo and in vitro. We observed in HUVEC monolayers that VEGF but not bFGF signaling promotes the tip cell phenotype. Untreated HUVECs in 


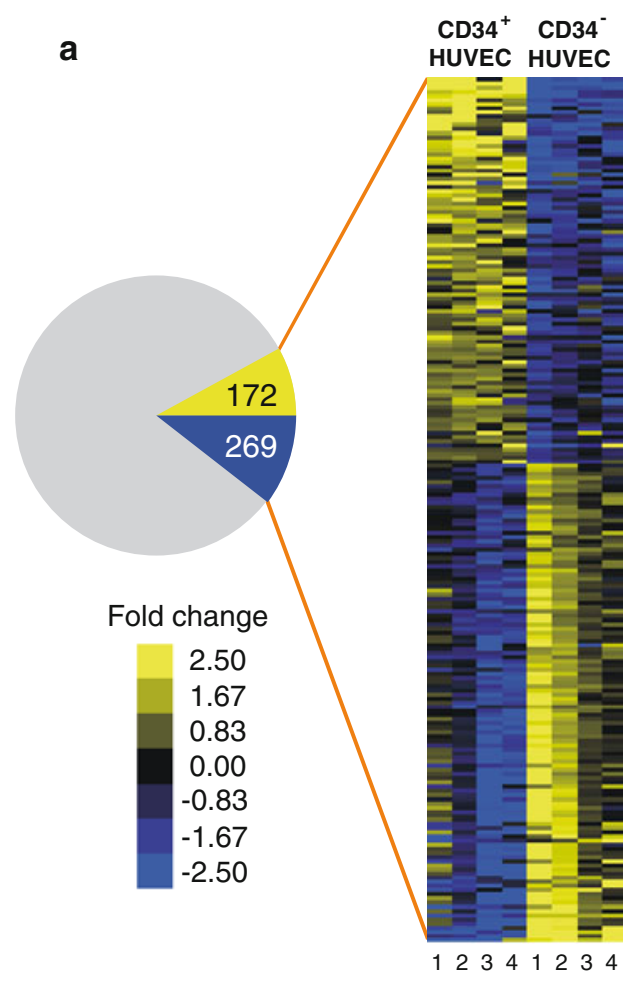

Fig. 7 Gene expression profiles of $\mathrm{CD} 34^{+}$HUVECs show features of a tip cell phenotype. a Pie chart (left) illustrating the number of genes with significantly $(Q$ value $<0.15)$ altered expression (total circle) between $\mathrm{CD}_{4} 4^{+}$and $\mathrm{CD} 34^{-}$fractions, and the 441 genes with significantly $(Q$ value $>0.15)$ increased (yellow part) or decreased (blue part) expression by more than 2 -fold. Heat map (right) of the

spheroids do not express CD34 [26, 40]. When we embedded HUVEC spheroids in collagen gel-containing FCS, CD34 expression was induced in endothelial cells at the surface of the spheroid by both VEGF and bFGF. Exposure to VEGF or bFGF induced three-dimensional in vitro sprouting angiogenesis in this assay, with CD34 expression on tip cell filopodia. This demonstrates that the tip cell phenotype and CD34 expression co-occur in angiogenesis in vitro. Our findings suggest that bFGF signaling alone stimulates angiogenesis but not necessarily the formation of tip cells. These differences in the effects of VEGF and bFGF stimulation in angiogenesis models in two and three dimensions require further study.

By culturing the FACS sorted $\mathrm{CD} 34^{-}$and $\mathrm{CD} 34^{+}$ fractions of HUVECs, we found that the expression of $\mathrm{CD} 34$ and maintenance of the $\mathrm{CD} 34^{+}$phenotype in vitro is an active and reversible process. Our results further indicate that formation of a subset of $\mathrm{CD} 34^{+}$cells in vitro is a common feature of endothelial cell cultures, even in immortalized cell lines after many passages. These findings are in accordance with data from in vivo studies on tip
441 differentially expressed genes in 4 HUVEC donors sorted for CD34 (yellow, induced; blue, repressed; $\log _{2}$ based scale). b GO analysis reveals a significant association of $\mathrm{CD} 34^{+}$cells with terms that are characteristic for tip cell functions and association of CD34 cells with terms of cell proliferation. $P$ values represent a BenjaminiHochberg-corrected EASE score. (Color figure online)

cells, which showed that tip cells are actively generated and that a dynamic competition between endothelial cells to become a tip cell occurs continuously [37]. It also shows that in general, culture conditions employed in endothelial cell cultures can be regarded as a pro-angiogenic environment.

Comparison of isolated $\mathrm{CD} 34^{+}$and $\mathrm{CD} 34^{-}$HUVEC populations showed increased gene expression of all presently known tip cell markers in $\mathrm{CD} 34^{+}$cells by qPCR. These results are again consistent with our hypothesis that this $\mathrm{CD}^{+} 4^{+}$population represents tip cells in vitro. Microarray analysis of the $\mathrm{CD} 34^{+}$and CD $34^{-}$HUVECs further demonstrated that $\mathrm{CD} 34^{+}$cells display a gene expression profile that is consistent with a tip cell phenotype. $\mathrm{CD} 34^{+}$cells were enriched for genes associated with biological functions such as "angiogenesis", "blood vessel development" and "regulation of cell migration", and $\mathrm{CD} 34^{-}$cells were enriched for genes associated with biological functions related to proliferation, including "cell cycle process" and "mitosis". Furthermore, we found a significant correlation between our microarray analysis and 
three gene sets from recent studies that investigated genomic profiles of vascular endothelial tip cells of various sources [5, 8, 25].

Our microarray analysis of the tip cell transcriptome as identified in CD34 ${ }^{+}$HUVECs has yielded a wealth of new data. For example, inhibition of CXCR4 signaling was recently shown by others to lead to defects in retinal tip cell morphology and reduction of intercellular connections between tip cells [8]. Our gene expression profile of $\mathrm{CD} 4^{+}$HUVECs confirmed this association. We observed co-expression of CXCL12 and CXCR4 which is consistent with the recent evidence indicating that the CXCL12CXCR4 signaling axis has an important role in tip cell formation and promotes an autocrine signaling mechanism in endothelial tip cells [8]. The secreted molecules IGF2, IGFBP4 and adrenomedullin were among the genes upregulated in $\mathrm{CD}^{+} 4^{+}$HUVECs. Consistent with this finding, secreted molecules also formed the largest cluster of tip cell-enriched genes identified by del Toro et al. [5], who suggested that these proteins are retained in the basal lamina surrounding stalk cells following tip cell to stalk cell transdifferentiation.

Our present study has characterized $\mathrm{CD} 34^{+}$cells in HUVEC cultures and established an in vitro model for the study of tip cell biology. Our results confirmed previous findings that CD34 is expressed in endothelial cell filopodia at sites of active angiogenesis in vivo. We showed in normal and pathological human tissues, in addition to the overall luminal vascular staining, striking CD34 staining of endothelial filopodial extensions at sites of active angiogenesis in vivo. Our study did not aim at unraveling the function of CD34 expression in tip cells. Recent evidence has indicated that CD34 acts as an anti-adhesive molecule during lumen formation in developing blood vessels, by maintaining or promoting the separation between contralateral apical endothelial cell surfaces in a luminal tube $[14,47]$. Although the function of CD34 in resting endothelial cells and in tip cells during angiogenesis was not addressed in the present study, we speculate that the proposed anti-adhesive property of CD34 may also play a role in maintaining vascular lumina in resting tissues, as well as in allowing the migration of tip cells and the movement and probing of their filopodia through the tissue matrix.

In summary, our findings suggest that the tip cell phenotype and CD34 expression co-occur in endothelial monolayers in vitro. Our results show that these CD34 ${ }^{+}$ cells in vitro are a valid tip cell model and that differential gene expression, functional characteristics and regulatory mechanisms of these cells are likely to predict properties of tip cells during angiogenesis. Along with the relative ease to obtain vascular endothelial cell cultures, our model allows for a convenient way to study effects of various types of blockers or promoters on tip cell phenotype and tip cell number. Furthermore, studies of the characteristics of $\mathrm{CD} 4^{+}$cells in vascular endothelial cell cultures will open new avenues for the study of molecular processes and functions in angiogenesis in general, and of the specialized endothelial tip cells in particular. By characterizing the transcriptome of tip cells in vitro we have identified a large number of tip cell-associated genes not previously published, in addition to the known genes previously associated with tip cells in vivo. These findings expand the tip cell gene expression profile and may contribute significantly to our future understanding of tip cell biology and angiogenesis.

Acknowledgments We thank Berend Hooibrink for assisting with the FACS experiments; Maaike van Berkel for assisting with the HUVEC spheroid angiogenesis model; and Jan Stap for help with the live cell imaging. This work was partially funded by the Dutch Association for the Prevention of Visually Impairment and Blindness, the Blindenpenning Foundation, the Dr. F. P. Fisher foundation, the Dutch National Foundation for the Visually Impaired and Blind, the Dutch Oogfonds Foundation, the Dutch Macular Degeneration Fund, and the Dutch Retina Foundation, combined in the Uitzicht grant 2009-18. The helpful editorial suggestions of Drs. Kelly McNagny and Michael Hughes (The Biomedical Research Center, University of British Columbia, Vancouver, BC, Canada) with respect to the manuscript are gratefully acknowledged as well as the assistance in the preparation of the final version of the manuscript by Monique Arendse.

Conflict of interest The authors declare no competing financial interests.

Open Access This article is distributed under the terms of the Creative Commons Attribution Noncommercial License which permits any noncommercial use, distribution, and reproduction in any medium, provided the original author(s) and source are credited.

\section{References}

1. Hillen F, Griffioen AW (2007) Tumour vascularization: sprouting angiogenesis and beyond. Cancer Metastasis Rev 26(3-4): 489-502

2. Siemerink MJ, Augustin AJ, Schlingemann RO (2010) Mechanisms of ocular angiogenesis and its molecular mediators. Dev Ophthalmol 46:4-20

3. Gerhardt H, Golding M, Fruttiger M, Ruhrberg C, Lundkvist A, Abramsson A, Jeltsch M, Mitchell C, Alitalo K, Shima D, Betsholtz C (2003) VEGF guides angiogenic sprouting utilizing endothelial tip cell filopodia. J Cell Biol 161(6):1163-1177

4. Hellstrom M, Phng LK, Hofmann JJ, Wallgard E, Coultas L, Lindblom P, Alva J, Nilsson AK, Karlsson L, Gaiano N, Yoon K, Rossant J, Iruela-Arispe ML, Kalen M, Gerhardt H, Betsholtz C (2007) Dl14 signalling through Notch1 regulates formation of tip cells during angiogenesis. Nature 445(7129):776-780

5. del Toro R, Prahst C, Mathivet T, Siegfried G, Kaminker JS, Larrivee B, Breant C, Duarte A, Takakura N, Fukamizu A, Penninger J, Eichmann A (2010) Identification and functional analysis of endothelial tip cell-enriched genes. Blood 116(19):4025-4033

6. Sawamiphak S, Seidel S, Essmann CL, Wilkinson GA, Pitulescu ME, Acker T, Acker-Palmer A (2010) Ephrin-B2 regulates 
VEGFR2 function in developmental and tumour angiogenesis. Nature 465(7297):487-491

7. Schlingemann RO, Rietveld FJR, Dewaal RMW, Bradley NJ, Skene AI, Davies AJS, Greaves MF, Denekamp J, Ruiter DJ (1990) Leukocyte antigen CD34 is expressed by a subset of cultured endothelial cells and on endothelial abluminal microprocesses in the tumor stroma. Lab Invest 62(6):690-696

8. Strasser GA, Kaminker JS, Tessier-Lavigne M (2010) Microarray analysis of retinal endothelial tip cells identifies CXCR4 as a mediator of tip cell morphology and branching. Blood 115(24):5102-5110

9. Tammela T, Zarkada G, Wallgard E, Murtomaki A, Suchting S, Wirzenius M, Waltari M, Hellstrom M, Schomber T, Peltonen R, Freitas C, Duarte A, Isoniemi H, Laakkonen P, Christofori G, YlaHerttuala S, Shibuya M, Pytowski B, Eichmann A, Betsholtz C, Alitalo K (2008) Blocking VEGFR3 suppresses angiogenic sprouting and vascular network formation. Nature 454(7204):656-660

10. Wang YD, Nakayama M, Pitulescu ME, Schmidt TS, Bochenek ML, Sakakibara A, Adams S, Davy A, Deutsch U, Luthi U, Barberis A, Benjamin LE, Makinen T, Nobes CD, Adams RH (2010) Ephrin-B2 controls VEGF-induced angiogenesis and lymphangiogenesis. Nature 465(7297):483-486

11. Witmer AN, Vrensen GF, Van Noorden CJ, Schlingemann RO (2003) Vascular endothelial growth factors and angiogenesis in eye disease. Prog Retinal Eye Res 22(1):1-29

12. Andrews RG, Singer JW, Bernstein ID (1986) Monoclonal-antibody $12-8$ recognizes A $115-\mathrm{Kd}$ molecule present on both unipotent and multipotent hematopoietic colony-forming cells and their precursors. Blood 67(3):842-845

13. Krause DS, Fackler MJ, Civin CI, May WS (1996) CD34: structure, biology, and clinical utility. Blood 87(1):1-13

14. Nielsen JS, McNagny KM (2009) CD34 is a key regulator of hematopoietic stem cell trafficking to bone marrow and mast cell progenitor trafficking in the periphery. Microcirculation 16(6):487-496

15. Baumhueter S, Dybdal N, Kyle C, Lasky LA (1994) Global vascular expression of murine $\mathrm{CD} 34$, a sialomucin-like endothelial ligand for L-selectin. Blood 84(8):2554-2565

16. Fina L, Molgaard HV, Robertson D, Bradley NJ, Monaghan P, Delia D, Sutherland DR, Baker MA, Greaves MF (1990) Expression of the CD34 gene in vascular endothelial cells. Blood 75(12):2417-2426

17. Lin GS, Finger E, Gutierrezramos JC (1995) Expression of CD34 in endothelial cells, hematopoietic progenitors and nervous cells in fetal and adult-mouse tissues. Eur J Immunol 25(6):1508-1516

18. Ruiter DJ, Schlingemann RO, Rietveld FJR, Dewaal MT, Dewaal RMW (1989) Monoclonal antibody-defined human endothelial antigens as vascular markers. J Invest Dermatol 93(2):25S-32S

19. Wood HB, May G, Healy L, Enver T, MorrissKay GM (1997) CD34 expression patterns during early mouse development are related to modes of blood vessel formation and reveal additional sites of hematopoiesis. Blood 90(6):2300-2311

20. Young PE, Baumhueter S, Lasky LA (1995) The sialomucin CD34 is expressed on hematopoietic cells and blood vessels during murine development. Blood 85(1):96-105

21. Hellwig SMM, Damen CA, van Adrichem NPH, Blijham GH, Groenewegen G, Griffioen AW (1997) Endothelial CD34 is suppressed in human malignancies: role of angiogenic factors. Cancer Lett 120(2):203-211

22. Delia D, Lampugnani MG, Resnati M, Dejana E, Aiello A, Fontanella E, Soligo D, Pierotti MA, Greaves MF (1993) CD34 expression is regulated reciprocally with adhesion molecules in vascular endothelial cells in vitro. Blood 81(4):1001-1008

23. van Beijnum JR, van der Linden E, Griffioen AW (2008) Angiogenic profiling and comparison of immortalized endothelial cells for functional genomics. Exp Cell Res 314(2):264-272
24. van der Schaft DWJ, Toebes EAH, Haseman JR, Mayo KH, Griffioen AW (2000) Bactericidal/permeability-increasing protein (BPI) inhibits angiogenesis via induction of apoptosis in vascular endothelial cells. Blood 96(1):176-181

25. Harrington LS, Sainson RCA, Williams CK, Taylor JM, Shi W, Li JL, Harris AL (2008) Regulation of multiple angiogenic pathways by Dll4 and Notch in human umbilical vein endothelial cells. Microvasc Res 75(2):144-154

26. Korff T, Augustin HG (1998) Integration of endothelial cells in multicellular spheroids prevents apoptosis and induces differentiation. J Cell Biol 143(5):1341-1352

27. Kuiper EJ, Hughes JM, Van Geest RJ, Vogels IM, Goldschmeding R, Van Noorden CJ, Schlingemann RO, Klaassen I (2007) Effect of VEGF-A on expression of profibrotic growth factor and extracellular matrix genes in the retina. Invest Ophthalmol Vis Sci 48(9):4267-4276

28. Klaassen I, Hughes JM, Vogels IM, Schalkwijk CG, Van Noorden CJ, Schlingemann RO (2009) Altered expression of genes related to blood-retina barrier disruption in streptozotocininduced diabetes. Exp Eye Res 89(1):4-15

29. Andersen CL, Jensen JL, Orntoft TF (2004) Normalization of real-time quantitative reverse transcription-PCR data: a modelbased variance estimation approach to identify genes suited for normalization, applied to bladder and colon cancer data sets. Cancer Res 64(15):5245-5250

30. Irizarry RA, Hobbs B, Collin F, Beazer-Barclay YD, Antonellis KJ, Scherf U, Speed TP (2003) Exploration, normalization, and summaries of high density oligonucleotide array probe level data. Biostatistics 4(2):249-264

31. Cui XQ, Churchill GA (2003) Statistical tests for differential expression in cDNA microarray experiments. Genome Biol 4(4):210

32. Storey JD, Tibshirani R (2003) Statistical significance for genomewide studies. Proc Natl Acad Sci USA 100(16):9440-9445

33. Hosack DA, Dennis G, Sherman BT, Lane HC, Lempicki RA (2003) Identifying biological themes within lists of genes with EASE. Genome Biol 4(10):R70

34. Huang DW, Sherman BT, Lempicki RA (2009) Bioinformatics enrichment tools: paths toward the comprehensive functional analysis of large gene lists. Nucleic Acids Res 37(1):1-13

35. Subramanian A, Tamayo P, Mootha VK, Mukherjee S, Ebert BL, Gillette MA, Paulovich A, Pomeroy SL, Golub TR, Lander ES, Mesirov JP (2005) Gene set enrichment analysis: a knowledgebased approach for interpreting genome-wide expression profiles. Proc Natl Acad Sci USA 102(43):15545-15550

36. Stap J, Krawczyk PM, Van Oven CH, Barendsen GW, Essers J, Kanaar R, Aten JA (2008) Induction of linear tracks of DNA double-strand breaks by alpha-particle irradiation of cells. Nat Methods 5(3):261-266

37. Jakobsson L, Franco CA, Bentley K, Collins RT, Ponsioen B, Aspalter IM, Rosewell I, Busse M, Thurston G, Medvinsky A, Schulte-Merker S, Gerhardt H (2010) Endothelial cells dynamically compete for the tip cell position during angiogenic sprouting. Nat Cell Biol 12(10):943-953

38. Witmer AN, van Blijswijk BC, Van Noorden CJ, Vrensen GF, Schlingemann RO (2004) In vivo angiogenic phenotype of endothelial cells and pericytes induced by vascular endothelial growth factor-A. J Histochem Cytochem 52(1):39-52

39. Sainson RCA, Johnston DA, Chu HC, Holderfield MT, Nakatsu MN, Crampton SP, Davis J, Conn E, Hughes CCW (2008) TNF primes endothelial cells for angiogenic sprouting by inducing a tip cell phenotype. Blood 111(10):4997-5007

40. Korff T, Augustin HG (1999) Tensional forces in fibrillar extracellular matrices control directional capillary sprouting. J Cell Sci 112(19):3249-3258

41. Barendsz-Janson AF, Griffioen AW, Muller AD, van Dam-Mieras MCE, Hillen HFP (1998) In vitro tumor angiogenesis assays: 
plasminogen lysine binding site 1 inhibits in vitro tumor-induced angiogenesis. J Vasc Res 35(2):109-114

42. Witmer AN, van Blijswijk BC, Dai J, Hofman P, Partanen TA, Vrensen GFJM, Schlingemann RO (2001) VEGFR3 in adult angiogenesis. J Pathol 195(4):490-497

43. Lu XW, le Noble F, Yuan L, Jiang QJ, de Lafarge B, Sugiyama D, Breant C, Claes F, De Smet F, Thomas JL, Autiero M, Carmeliet P, Tessier-Lavigne M, Eichmann A (2004) The netrin receptor UNC5B mediates guidance events controlling morphogenesis of the vascular system. Nature 432(7014):179-186

44. Koch AW, Mathivet T, Larrivee B, Tong RK, Kowalski J, Pibouin-Fragner L, Bouvrée K, Stawicki S, Nicholes K, Rathore N, Scales SJ, Luis E, del Toro R, Freitas C, Breant C, Michaud A, Corvol P, Thomas JL, Wu Y, Peale F, Watts RJ, Tessier-Lavigne M, Bagri A, Eichmann A (2011) Robo4 maintains vessel integrity and inhibits angiogenesis by interacting with UNC5B. Dev Cell 20(1):33-46

45. Martyn U, Schulte-Merker S (2004) Zebrafish neuropilins are differentially expressed and interact with vascular endothelial growth factor during embryonic vascular development. Dev Dyn 231(1):33-42

46. Gerhardt H, Ruhrberg C, Abramsson A, Fujisawa H, Shima D, Betsholtz C (2004) Neuropilin-1 is required for endothelial tip cell guidance in the developing central nervous system. Dev Dyn 231(3):503-509

47. Strilic B, Kucera T, Eglinger J, Hughes MR, McNagny KM, Tsukita S, Dejana E, Ferrara N, Lammert E (2009) The molecular basis of vascular lumen formation in the developing mouse aorta. Dev Cell 17(4):505-515 